resection. Beghetti and associates ${ }^{5}$ reported that palliative superior cavopulmonary anastomosis was effective and functioned well for 2 years in a patient with huge right ventricular fibroma. As for methodology of superior cavopulmonary anastomosis, bidirectional Glenn anastomosis is preferred to hemi-Fontan procedure because the superior vena cava should be disconnected from the right atrium to guard cavopulmonary anastomosis against tumor extension into the right atrium or right atrial thrombus secondary to right ventricular obstruction.

Although surgical excision does not cure the primary disease in metastatic tumors of the heart, palliative resection may be justified for immediate life-threatening danger due to an intracavity space-occupying lesion. Additional bidirec- tional cavopulmonary anastomosis may provide assurance in long-term pulmonary blood flow in unresectable cardiac metastasis.

\section{References}

1. Brandley SM, Bolling SF. Late renal cell carcinoma metastasis to the left ventricular outflow tract. Ann Thorac Surg. 1995;60:204-6.

2. Roigas J, Schroeder J, Rudolph B, Schnorr D. Renal cell cancer with a symptomatic heart metastasis. Br J Urol. 2002;90:622-3.

3. Sobue T, Iwase M, Aoki T, Noda A, Tanaka M. Solitary left ventricular metastasis of renal cell carcinoma. Am Heart J. 1993;125:1801-2.

4. Kruger I, Borowski A, Horst M, Vivie ER, Theissen P, Gross-Fengels W. Symptoms, diagnosis, and therapy of primary sarcomas of the pulmonary artery. Thorac Cardiovasc Surg. 1990;38:91-5.

5. Beghetti M, Haney I, Williams WG, Mawson J, Freedom RM. Massive right ventricular fibroma treated with partial resection and a cavopulmonary shunt. Ann Thorac Surg. 1996;62:882-4.

\title{
Repair for acute type A aortic dissection with a long elephant trunk technique
}

Hiroki Hata, MD, PhD, Koichi Toda, MD, PhD, Yasuhiro Shudo, MD, Satoshi Kainuma, MD, Kiyoshi Yoshida, CE, Keiji Yamamoto, CE, and Kazuhiro Taniguchi, MD, PhD, Sakai, Japan

Total arch replacement (TAR) is often performed for acute type A aortic dissection (AAAD) involving the aortic arch. ${ }^{1}$ However, because conventional TAR including the use of a short elephant trunk ${ }^{2,3}$ requires careful dissection of the surrounding tissue and elaborate distal anastomosis at the site of dissection and occasionally at the site of the aneurysm, there could be some cases in which bleeding is uncontrollable or circulatory arrest time is prolonged. To reduce such problems, we applied TAR with distal anastomosis just proximal to the innominate artery using a long elephant trunk (LET) technique, which we $\mathrm{e}^{4,5}$ have introduced for true arch aneurysms and chronic aortic dissections.

\section{CLINICAL SUMMARY}

Four consecutive patients with AAAD (3 men) underwent surgical repair, from March 2006 to January 2007, with TAR using the LET technique. The mean age was 62 years (range, 51-71 years). Preoperative computed tomography (CT) and transesophageal echocardiography revealed that in all cases

\footnotetext{
From the Department of Cardiovascular Surgery and Clinical Engineering Section, Japan Labour Health and Welfare Organization, Osaka Rosai Hospital, Sakai, Japan. Received for publication Dec 18, 2007; revisions received June 13, 2008; accepted for publication July 6, 2008.

Address for reprints: Kazuhiro Taniguchi, MD, PhD; 1179-3, Nagasone-cho, Kita-ku, 591-8025 Sakai, Japan (E-mail: hatahiro1019@yahoo.co.jp).

J Thorac Cardiovasc Surg 2009;137:777-8

0022-5223/\$36.00

Copyright (C) 2009 by The American Association for Thoracic Surgery

doi:10.1016/j.jtcvs.2008.07.058
}

the entry site was located in the ascending aorta near the innominate artery. All cases were DeBakey type I. There were not any dissection-related complications.

TAR using a 4-branched Hemashield arch graft (Hemashield Platinum, Woven Double Velour; Boston Scientific, Wayne, NJ) was done through a median sternotomy, similar to previously reported methods. ${ }^{4}$ In brief, after minimal dissection of the ascending aorta and arch vessels, extracorporeal circulation was established with bicaval venous drainage and a right axillary artery return via an anastomosed 8-mm graft. After cardiac arrest with retrograde cold blood cardioplegia, the ascending aorta was transected above the sinotubular junction and a minimal amount of gelatinresorcin-formalin glue was used in the proximal false lumen. After placement of a running suture in the aortic edge to fix the intima tightly, an appropriately sized 4-branched graft was anastomosed with interrupted pledget-supported sutures and an additional running suture. Then, under moderately hypothermic $\left(25^{\circ} \mathrm{C}\right)$ circulatory arrest with antegrade selective cerebral perfusion, ${ }^{4}$ the ascending aorta was declamped and the LET was pulled into the true lumen of the dissected aorta with a catching catheter (Amplatz Goose-Neck Snare; ev3 Inc, Plymouth, Minn) that was introduced from the true lumen of the femoral artery (Figure 1, $A$ ). Next, an open distal anastomosis was performed at the base of the innominate artery without glue and reinforced with a felt strip (Figure 1,B). Antegrade systemic perfusion was resumed through the 

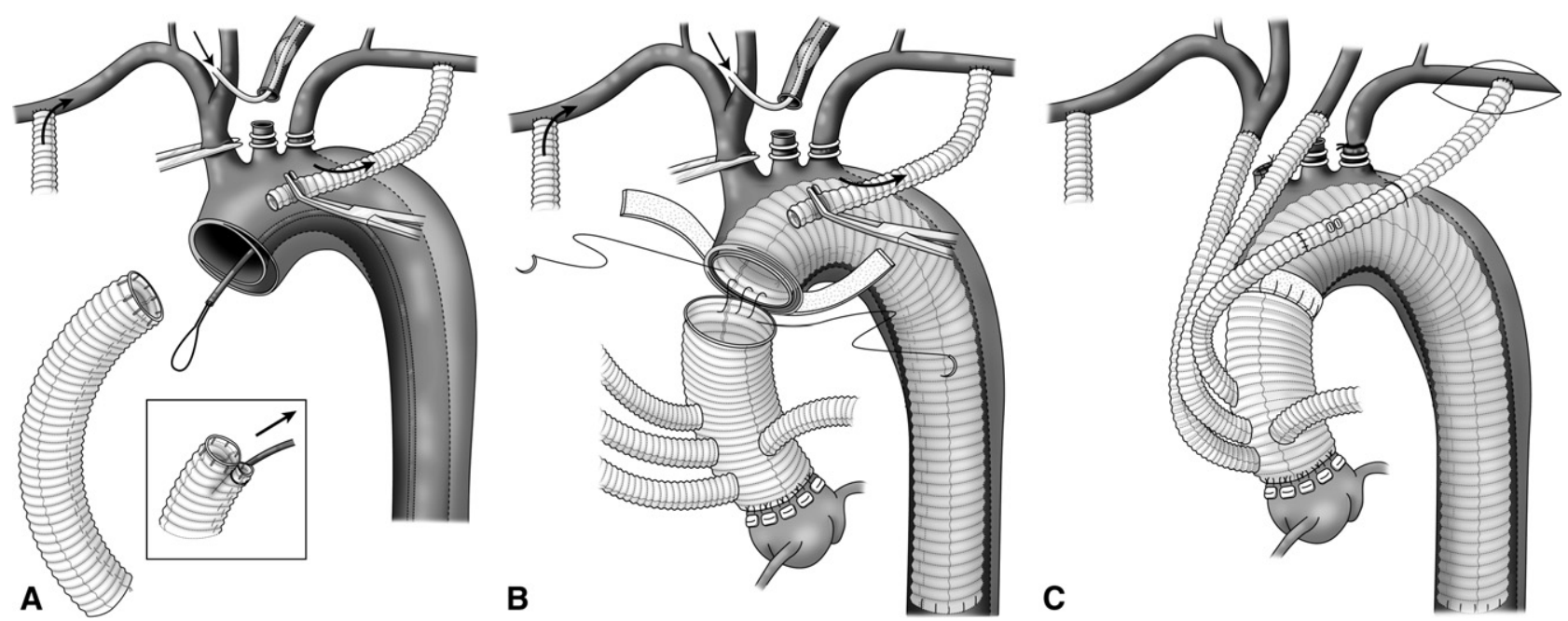

FIGURE 1. A, Antegrade selective cerebral perfusion was initiated with 8 -mm grafts anastomosed to the bilateral axillary arteries and a $12 \mathrm{~F}$ balloon catheter inserted into the left common carotid artery. The graft to the left axillary artery was previously guided into the pericardial space through a retroclavicle tunnel. A catching catheter was introduced from the femoral artery through the true lumen. A 2-0 Tevdek suture (Deknatel, Inc, Fall River, Mass) was placed onto the lesser curvature of the elephant trunk so as to fix its length and prevent stretching and covering the orifices of distal intercostal arteries. B, A long elephant trunk was pulled into the true lumen and an open distal anastomosis was performed at the base of the innominate artery. C, The arch vessels were sequentially reconstructed. The stump of the innominate artery was closed with two pledget-supported sutures and an additional continuous suture.

fourth side branch of the graft. Finally the arch vessels were reconstructed by an end-to-end anastomosis to each branch of the graft (Figure 1,C). The mean myocardial ischemic time, open distal time, and antegrade selective cerebral perfusion time were $142 \pm 25,37 \pm 10$, and $93 \pm 20$ minutes, respectively. The length of the LET was $14 \mathrm{~cm}$ in 3 patients and $13 \mathrm{~cm}$ in the other; the diameter was $22 \mathrm{~mm}$ in all patients. The tip of the LET, on which small surgical clips were placed, was confirmed on CT as being between the Th7 and Th9 levels. There were neither neurologic complications such as stroke, paraplegia, and recurrent or phrenic nerve palsy, nor malperfusion of organs. The false lumen from the distal anastomosis to the proximal visceral branch was revealed to be thrombosed by CT within 1 month after the operation. Until the end of October 2008, all patients were alive without significant cardiovascular events. No progress of the dilatation of the downstream aorta was seen on further follow-up CT scans.

\section{DISCUSSION}

So far, we have demonstrated the effectiveness of TAR with the LET for chronic lesions. ${ }^{4,5}$ This is the first report that discloses its utility in regard to AAAD. Of course, the elephant trunk technique has been already used for AAAD to prevent late enlargement of the residual aortic dissection., ${ }^{2,3}$ However, the length was usually less than $10 \mathrm{~cm}$, whereas we applied a longer elephant trunk with a length of 13 to $14 \mathrm{~cm}$. Our strategy was well characterized by not touching the unmanageable aortic arch and descending aorta. Because distal anastomosis was performed just at the base of the innominate artery, we could relatively simply accomplish TAR in almost the same viewing field as for a graft replacement of the ascending aorta with a shorter open distal time than with conventional TAR. ${ }^{1,2}$ In other words, we did not need to expose any enlarged, fragile, or hemorrhagic tissue or a deeper part of the dissecting aortic arch or descending aorta.

In conclusion, compared with the conventional TAR including the short elephant trunk technique, our technique may save more open distal time and be more safe and reliable with less morbidity even in AAAD, for which most cardiovascular surgeons may hesitate to perform urgent TAR. Further cases with long-term follow-up are required to confirm its superiority.

\section{References}

1. Ochiai Y, Imoto Y, Sakamoto M, Ueno Y, Sano T, Baba H, et al. Long-term effectiveness of total arch replacement for type A aortic dissection. Ann Thorac Surg. 2005;80:1297-302.

2. Watanuki H, Ogino H, Minatoya K, Matsuda H, Sasaki H, Ando M, et al. Is emergency total arch replacement with a modified elephant trunk technique justified for acute type A aortic dissection? Ann Thorac Surg. 2007;84:1585-91.

3. Miyamoto S, Hadama T, Anai H, Wada T, Iwata E, Tanaka H, et al. Simplified elephant trunk technique promotes thrombo-occlusion of the false lumen in acute type A aortic dissection. Ann Thorac Cardiovasc Surg. 2006;12:412-6.

4. Taniguchi K, Toda K, Hata H, Shudo Y, Matsue H, Takahashi T, et al. Elephant trunk anastomosis proximal to origin of innominate artery in total arch replacement. Ann Thorac Surg. 2007;84:1729-34.

5. Kuki S, Taniguchi K, Masai T, Yokota T, Yoshida K, Yamamoto K, et al. An alternative approach using long elephant trunk for extensive aortic aneurysm: elephant trunk anastomosis at the base of the innominate artery. Circulation. 2002;106(Suppl I):I253-8. 